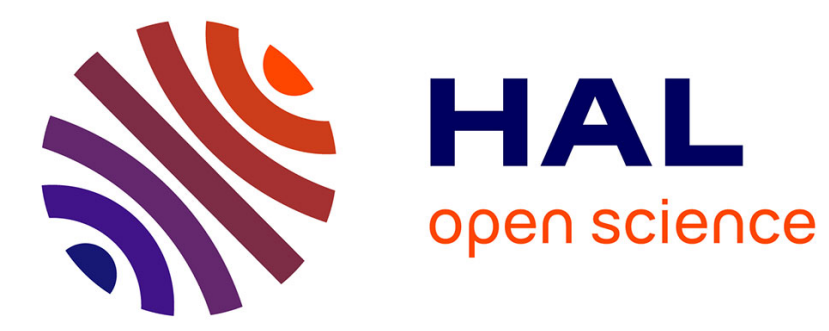

\title{
DETERMINATION OF THE DYNAMIC RESPONSE OF A NITRIDE GLASS PARTICULATE COMPOSITE
}

\author{
Y. Yeshurun, D. Brandon, M. Farkash, Z. Rosenberg
}

\section{To cite this version:}

Y. Yeshurun, D. Brandon, M. Farkash, Z. Rosenberg. DETERMINATION OF THE DYNAMIC RESPONSE OF A NITRIDE GLASS PARTICULATE COMPOSITE. Journal de Physique IV Proceedings, 1991, 01 (C3), pp.C3-101-C3-108. 10.1051/jp4:1991313 . jpa-00249935

\section{HAL Id: jpa-00249935 https://hal.science/jpa-00249935}

Submitted on 1 Jan 1991

HAL is a multi-disciplinary open access archive for the deposit and dissemination of scientific research documents, whether they are published or not. The documents may come from teaching and research institutions in France or abroad, or from public or private research centers.
L'archive ouverte pluridisciplinaire HAL, est destinée au dépôt et à la diffusion de documents scientifiques de niveau recherche, publiés ou non, émanant des établissements d'enseignement et de recherche français ou étrangers, des laboratoires publics ou privés. 


\title{
DETERMINATION OF THE DYNAMIC RESPONSE OF A NITRIDE GLASS PARTICULATE COMPOSITE
}

\author{
Y. YESHURUN* , D.G. BRANDON** , M. FARKASH* ${ }^{*}$ and Z. ROSENBERG* \\ *RAFAEL, P.O. Box 2250 (24), Haifa 31021, IsraëI \\ * "Department of Materials Engineering, Technion-Israë1 \\ Institute of Technology, IL-Haifa 32000, IsraëI
}

Résumé - Le développement des céramiques avancées mise en oeuvre dans des applications où les vitesses de déformations sont élevées a suscité un intérêt pour la mesure de leurs caractéristiques dynamiques. Des essais d'impacts plans ont été mise en oeuvre sur une vitrocéramique obtenue par pressage à chaud à base de renforts SIC et d'une matrice verre oxydonitrurée. Les éprouvettes présentent une porosité inférieure à $2 \frac{9}{b}$ en volume. Ie renfort SIC, en poudre, est chimiquement inerte vis à vis de la matrice, mais cependant jamais complétement mouillé et dispersé de façon homogène. Des mesures de caractéristiques statiques et dynamiques ont été effectuées à la fois pour le verre nitruré monolithique, et pour le composite. Des courbes d'Hugoniot ont été établies grâce à des jauges au Mangania dans la gamme du composite s'est révélée être, à peu de choses près, celle déterminées par la loi des mélanges, alors que la limite élastique d'Hugoniot (IEH) du composite $(9,2$ GPa) est assez proche de celle du verre. Par ailleurs la ténacité et la résistance à la flexion du composite sont largement supérieures aux valeurs correspondantes mesurées pour le verre.

\begin{abstract}
The development of advanced ceramics for high strain rate applications has generated an interest in the measurement of the dynamical mechanical properties of these materials. Planar impact experiments were performed on a hot-pressed particulate composite of an oxynitride glass matrix with 50 wt\% Sic filler. The samples contained less than 2 vol\% porosity. The SiC filler powder was chemically inert in the oxynitride glass but was nevertheless completely wetted and homogeneously dispersed. Static and dynamic mechanical properties were measured for both the monolithic glass matrix and the particulate composite. Huganiot curves were determined in the shock pressure range from 2.5 to $10 \mathrm{GPa}$ using manganin gauges. The shock impedance of the composite was approximately that expected from the law of mixtures while the Hugoniot elastic limit (HEL) of the composite, $9.2 \mathrm{GPa}$, was clase to that of the parent glass. On the otherhand, the toughness and bend strength of the composite greatly exceeded those of the parent glass.
\end{abstract}




\section{INTRODUCTION}

The dependence of the material particle velocity on the compressive impact pressure is a characteristic of the material. The curve is the dynamic equivalent of a static stress-strain curve, in which the elastic impedance governs the initial slope in place of the elastic modulus. The dynamic properties of major importance in the selection of ceramic armor materials are the elastic impedance and the HEL. other material properties of significance are the density, the elastic modulus and the static compressive strength or hardness. However these properties are themselves related to the dynamic properties. Ceramics with high impedance and high HEL in general exhibit high modulus, high compressive strength (or hardness) and high density.

Several attempts have been made to introduce glasses into armor systems. The primary disadvantages of glass are their low elastic modulus (which reduces their impedance) and fracture toughness when compared to crystalline ceramics. This is partly compensated by the lower density of the more open amorphous structure. A more important effect is an elastic softening which has been observed in some glasses subjected to high pressures. This leads to a curvature of the Hugoniot in the elastic region which is the inverse of that usually observed and results in dispersion of the primary shock wave.

Nitrogen containing glasses are of particular interest, since they have been found to have a high elastic modulus [1]. Furthermore, nitrogen glasses based on yttria additions also have higher densities, so that they offer a possibility of achieving a reasonable impedance match with conventional ballistic ceramics. The Huganiot curve for selected oxynitride glasses has been determined by the authors and the value of the HEL was found to be exceptionally high and well into the range considered desirable for ceramic materials intended for high strain rate applications [2].

The basic problem associated with the preparation of oxynitride glasses is the suppression of the evolution of nitrogen gas during melting of the glass [3]. This can be achieved by applying an overpressure of nitrogen, by adding free silicon metal to the glass, or by adding stabilising oxides (especially $Y_{2} \mathrm{O}_{3}$ ) [4, 5]. Nitrogen contents of a few percent are quite stable at normal glass melting temperatures, but the viscosity rises rapidly with nitrogen content, and glass melting at nitrogen contents exceeding 10 at.\% is only possible at temperatures exceeding $1700^{\circ} \mathrm{C}[1,4]$. While $5 \mathrm{wt} . \%$ of silicon metal is sufficient to suppress nitrogen evolution at atmospheric pressure from a Mgo containing glass, nearly 50 wt\% of $\mathrm{Y}=\mathrm{O} 3$ is required to suppress nitrogen evolution in nitrogen glasses containing 6 to 15 at.\% nitrogen.

The elastic properties of yttria-based oxynitride glasses were determined by Messier [1], who also confirmed that the materials remained free of crystalline phases for nitrogen contents of up to 15 at.\%. The elastic modulus was found to increase from $141 \mathrm{GPa}$ at 6.3 at.\% nitrogen to $186 \mathrm{GPa}$ at 15.0 at.\% nitrogen. The density of these yttria-containing compositions varied from 3.82 to $4.0 \mathrm{gm} . \mathrm{cm}^{-3}$. The mechanical impedance is thus some $50 \%$ less than that of a good ballistic alumina. This may be compared to a normal borosilicate glass, with a density of 2.55 and an elastic modulus of $60 \mathrm{GPa}$, corresponding to an impedance one third that of alumina and only half that of the oxynitride glass compositions.

The authors determined the Hugoniot curves of two oxynitride glasses prepared by Messier and confirmed their high impedance [2]. 
Moreover, the values of the HEL were found to be 9.0 and $10.4 \mathrm{GPa}$ for the 6.0 and 13.3 at.\% nitrogen glasses respectively, comparable to the HEL of a high purity alumina [6]. Finally, the measured stress signals in the high stress range showed that the transmitted compressive shock waves were composed of an initial elastic jump followed a slower, 'plastic' wave. This behaviour is indicative of some dispersive behaviour not normaliy seen in a ceramic target. In addition, the estimated spall strength for both glass compositions was of the order of $0.8 \mathrm{GPa}$, decreasing to zero at the HEL. This is higher than the spall strength reported for alumina ceramics $(0.3$ to $0.4 \mathrm{GPa})$ [7].

A major factor in the development of ballistic ceramics is the effect of impedance mismatch at internal boundaries on the ballistic properties [8]. In general, shockwaves are expected to be scattered by all such boundaries, leading to the development of high internal stresses. These internal stresses will lead to cumulative damage and eventual failure. For this reason, monolithic, single-phase ceramics have been the materials of first choice for high strain-rate applications. For the same reason, residual porosity is regarded as a major microstructural defect, since a pore is the most effective microstructural feature for the scattering of a shockwave. Or the other hand, the presence of a second phase may serve to improve the microstructural homgeneity and inhibit undesirable grain growth, so that it is not immediately obvious that the addition of the second phase is necessarily deleterious to the dynamic properties. In the case of an oxynitride glass, the addition of a ceramic filler material with a suitabiy matched impedance may be expected to improve the toughness, while the ballistic properties (the HEL and the spall strength) remain uneffected. It is to verify these expectations that the present project was undertaken.

\section{EXPERIMENTAL METHODS}

\subsection{Materials}

The static and dynamic properties of the oxynitride glasses were previously investigated by Messier and the authors [1, 2], and their compositions are given in wt.\% in Table 1.

Table 1 - Oxynitride glasses.

\begin{tabular}{lrr} 
wt.\% & ' $a$ ' & \multicolumn{1}{c}{ 'b' } \\
\hline $\mathrm{Al}_{2} \mathrm{O}_{3}$ & 11.5 & 23.83 \\
$\mathrm{Si} \mathrm{N}_{4}$ & 7.91 & 16.39 \\
$\mathrm{SiO}_{3}$ & 30.06 & 7.02 \\
$\mathrm{Y}=3$ & 50.53 & 52.77 \\
$(\mathrm{~N})$ & 3.16 & 6.56 \\
\hline
\end{tabular}

Three ceramic filler materials were considered for these glasses: $\mathrm{BaC}_{\mathrm{C}} \mathrm{SiC}$ and $\mathrm{TiB}=$, these being the three non-oxide monolithic ceramics with the best known high strain-rate performance.

\subsection{Planar Impact Tests}

The planar impact experiments were conducted in a $2.5 \mathrm{in}$. gas gun described elsewhere [9]. The experimental assembly is shown schematically in Fig.1. Impact velocities were measured to an accuracy 
of $\pm 0.5 \%$ and ranged between 100 and $700 \mathrm{~m} . \mathrm{s}^{-1}$, corresponding to shock pressures in the range 2.5 to $12.0 \mathrm{GPa}$ for a copper impactor. The manganin gauges (M.M., type LM-SS-125cH sp60) were calibrated under both loading and unloading conditions $[10,11]$. These references also give details of gauge emplacement and data reduction proceedures. The gauges are grid-like foils $0.5 \mu \mathrm{m}$ thick deposited on $0.04 \mathrm{~mm}$ epoxy sheet. The gauges were either glued between two lapped plates of the oxynitride glass composite, or between a single disc of the composite and a poly (methyl-methacrylate) (PMMA) backing plate. In the first configuration, designated 'in-material', we obtain points on the Hugoniot curve, while from the second, 'back- surface' configuration we are generally able to evaluate the spali-strength and the HEL of the specimens.

\section{RESULTS}

\subsection{Mechanical Properties of Selected Compositions}

The strength (MOR), hardness and toughness of the oxynitride glass were all found to be greatly improved by the addition of sic filler powder. Representative values are given in Table 2.

Table 2 - Mechanical Properties

\begin{tabular}{lccc}
\hline Filler wt\% & $15 \%$ SiC & $29 \%$ SiC & $50 \%$ SiC \\
Part.Size & $<15 \mu \mathrm{m}$ & $<15 \mu \mathrm{m}$ & $<2 \mu \mathrm{m}$ \\
Dens.g.cm- & 3.55 & 3.53 & 3.32 \\
MOR MPa & $112 \pm 21$ & $174 \pm 30$ & $310 \pm 50$ \\
VHN Hr & $758 \pm 27$ & $992 \pm 57$ & $1048 \pm 55$ \\
Re MPa $\sqrt{ }$ & $2.1 \pm 0.4$ & $2.4 \pm 0.5$ & $3.9 \pm 0.2$ \\
E GPa & - & - & 245 \\
\hline
\end{tabular}

These mechanical properties are far better than could be obtained without the addition of a filler. Although the toughness is low compared to high performance ceramics, it is comparable to that of commercial grades of alumina tiles. Similarly, although the hardness is low it is also comparable to commercial grades of alumina containing approximately $90 \% \mathrm{Al}_{2} \mathrm{O}_{3}$. The mechanical strength (MOR) is again comparable to that obtained from a good quality structural alumina tile.

\subsection{Dynamic Properties}

The 50mm diameter sample plates of the oxynitride glass containing approximately 50 vol\% SiC powder filler were tested in planar impact, using both the 'in-material' and the 'back-surface test configurations.

The 'in-material' configuration provides an accurate measure of the impact pressure and the accompanying particle velocity of the material. For each projectile velocity, such a test thus gives a point on the Hugoniot curve. The 'back-surface' configuration, on the other hand, is very sensitive to any changes in wave velocity, such as occur at the Hugoniot elastic limit (HEL).

In the present work it has not proved possible to derive any information concerning the spall-strength. Such information is normally obtained from the pull-back signal observed in the 
'back-surface' configuration, and no clear pull-back signal was obtained in the present experiments. An example of the signal pulse obtained in the back-surface configuration is given in Fig.2. This signal was obtained using a copper impactor at a velocity of 615 $\mathrm{m} \cdot \mathrm{s}^{-1}$. The verticle scale is $0.2 \mathrm{~V} \cdot \mathrm{cm}^{-1}$ and the horizontal (time) scale is 0.5 us. $\mathrm{cm}^{-1}$.

The results of the planar impact tests are summarised in Fig. 3 , which compares the Hugoniot curve derived for the particulate composite oxynitride glass/sic specimens with both the Hugoniot derived for the glass alone [2] and the Hugoniot for a high performance alumina (AD 99) [6]. The impedance of the composite is significantly greater than that of the parent glass, and is in fact somewhat higher than would have been expected on the basis of a simple law of mixtures rule. The HEL, on the other hand, is, within experimental limits, identical to that of the parent glass. Since the parent glass wets the SiC filler completely, this latter result is not unexpected.

\section{DISCUSSION}

The work reported here is from an investigation comprising three topics:

1. The compatibility of non-oxide ceramic filler powders with yttria-based oxynitride glasses.

2. The development of procedures for hot-pressing particulate ceramic composites based on oxynitride glass.

3. The measurement of the dynamic properties of oxynitride glass matrix particulate composites by planar impact.

The restrictions imposed on the processing route used in the present programme were, principally, the composition of the oxynitride glass and the environment of the hot-press. Only the glass compositions previously investigated by Messier were studied, since these were the materials whose dynamic properties were available [2]. The hot-press was operated at ambient atmosphere with carbon black insulation. Only one glass composition was microstructurally stable, containing 6.3 at\% of nitrogen, while the higher nitrogen content glass always contained some porosity associated with gas evolution during sintering.

As suspected from the relative thermodynamic stability of the oxides and carbides of silicon and boron, boron carbide was found to be unstable under the conditions required for glass formation, while silicon carbide was found to be completely stable. No evidence for any reaction with SiC was found, even at the limit of detection in the transmission electron microscope (of the order of 1-2nm). Reaction of the oxynitride glass with titanium diboride was observed, although the borides are inherently less stable than the carbides and nitrides of the same metal. Since the reaction products are in this case all solid, the reaction with $\mathrm{TiB}_{z}$ is not a barrier to the formation of particulate composites. The titanium compounds which have been identified were all aluminium containing, consistent with the known stability of the titanium aluminides and suggesting that an alumina-free glass composition might be less reactive.

The mechanical properties of both the SiC and the TiBz containing composites were satisfactory, but both the static and the dynamic properties obtained from the material containing 50 vol\% of fine grained SiC were appreciably better than the other compositions and were comparable to those of a goad alumina armour tile manufactured from a monolithic ceramic. 


\section{CONCLUSIONS}

1. An oxynitride glass containing 6.3 at\% nitrogen is incompatible with $a$ BaC filler powder, reacts significantly with a TiB $B_{z}$ filler powder and is inert to sic filler powders at the temperatures required for glass formation.

2. The addition of a SiC filler powder to this same oxynitride glass results in a significant improvement in the modulus of rupture, fracture toughness and hardness of the glass. The maximum improvement in mechanical properties was observed for a 50 vol\% particulate composite with a fine grained silicon carbide.

3. Large disc specimens of a particulate, 6.3 at\% $\mathrm{N}$, oxynitride glass composite containing 50 vol\% sic can be prepared free of processing defects by hot-pressing, provided careful attention is paid to the powder preparation and hot-pressing parameters.

4. The high strain rate properties of this particulate composite are comparable or better than those of the oxynitride glass matrix.

\section{REFERENCES}

1. D.R.Messier \& A.Broz, Comm.Am.Ceram.Soc., 65, C-123 (1982)

2. Y.Yeshurun \& D.G.Brandon, 'The dynamic response of oxynitride glass', Report to AMTL, Watertown, Dec. 1986

3. R.A.L.Drew, S.Hampshire, and K.H.Jack, 'The preparation and properties of axynitride glass', Riley F.L. (ed) Progress in Nitrogen Ceramics, Martinus Nijhoff, p.323 (1983)

4. D.R.Messier, Cer.Eng.Sci.Proc., 3, 565 (1985)

5. J.Rocherulle, J.Guyader, P.Verdier \& Y.Laurent, J.Mat.Sci., 24, 4525 (1989)

6. L.Davison \& R.A.Graham, Phys.Rep.SS 255 (1979)

7. Y.Yeshurun, D.G.Brandon, A.Venkeret \& Z.Rosenberg, J. de Phys., $49[\mathrm{C}-3], 11$ (1988)

8. Y.Yeshurun, Z.Rasenberg and D.G.Brandon, Proc. 4th Int.Conf. on Mechanical Properties at High Rates of Strain, Oxford 1989, Inst. Physics (1989)

9. Y.Porat \& M.Gvishi, J.Phys.E, 13, 504 (1980)

10. Z.Rosenberg, D.Yaziv \& Y.Partom, J.Appl.Phys., 51, 3702 (1980)

11. D.Yaziv, Z.Rosenberg \& Y.Partom, J.Appl.Phys., 51, 6055 (1980)

\section{ACKNOWLEDGEMENTS}

This work was supported by the European research office of the United States Army under contract \# DAJA45-88-C-0007. 


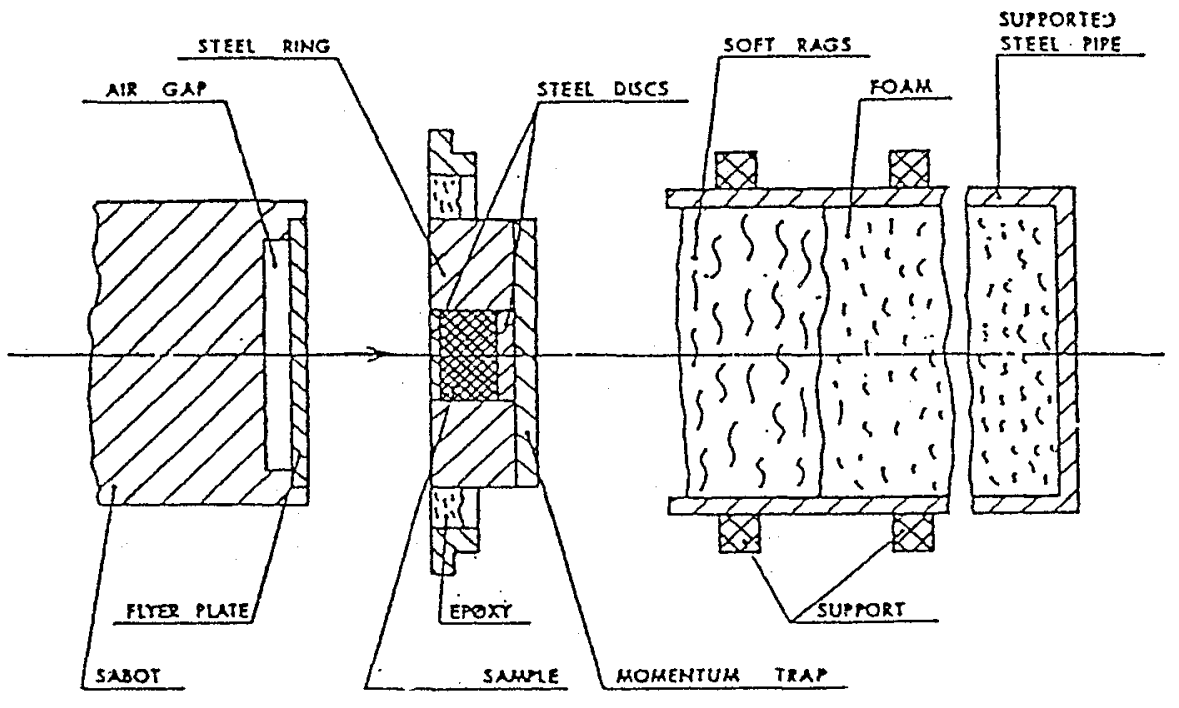

Fig.1 Projectile and target assemblies, and target recovery system.

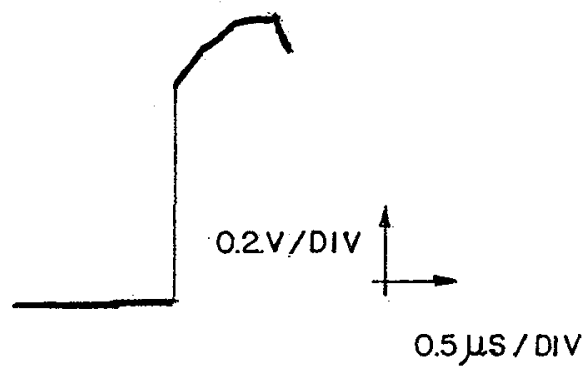

Fig.2 Pulse record from a 'back-surface' gauge impact test. 


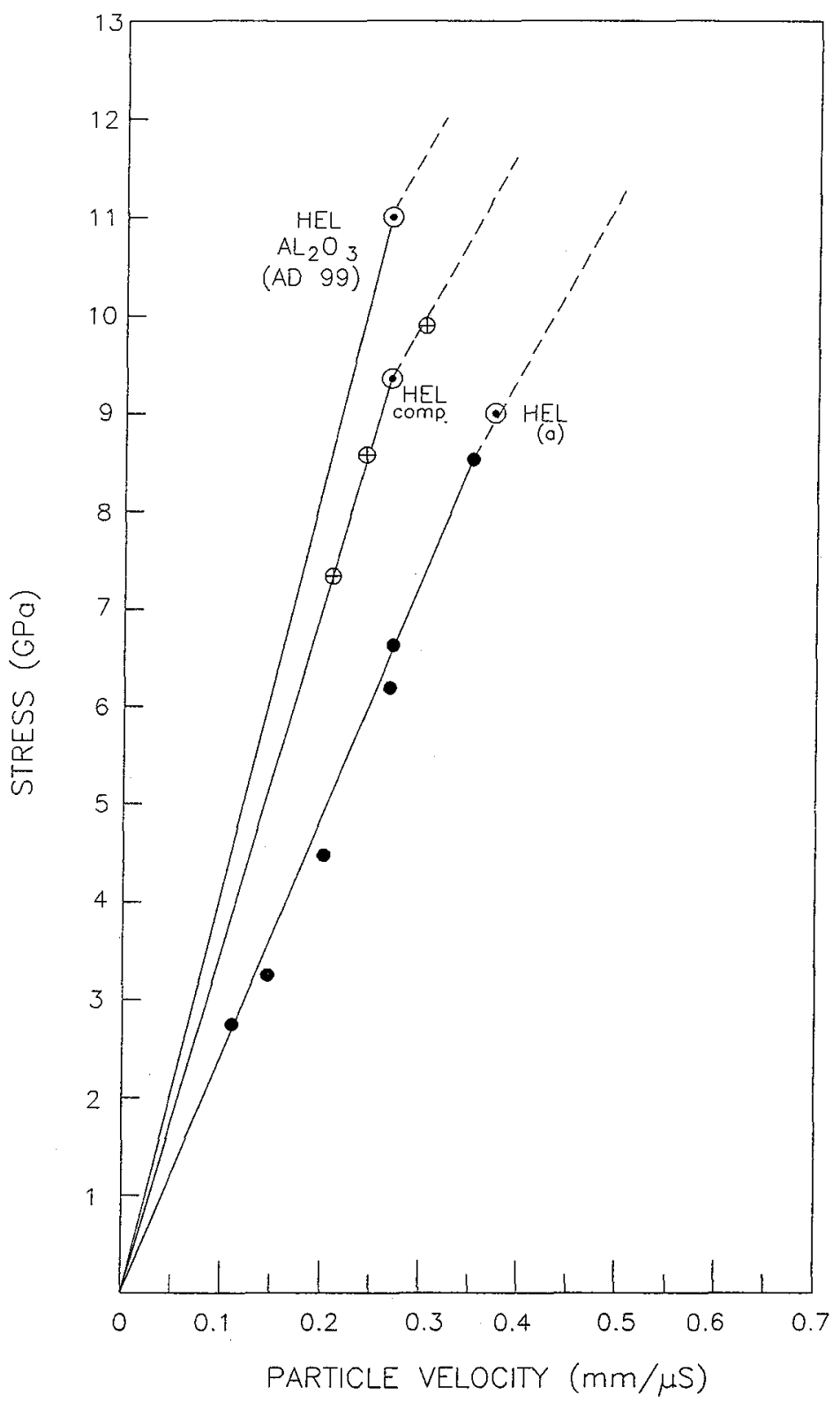

Fig.3 Hugoniat curve for the particulate composite compared with that of the oxynitride glass and that of $99.9 \% \mathrm{Al}=\mathrm{O}$. 